\title{
Effects of recent strategies of selective collection on the design of municipal solid waste treatment plants in Italy
}

\author{
M. Ragazzi \& E. C. Rada \\ Department of Civil and Environmental Engineering, \\ Trento University, Italy
}

\begin{abstract}
In Italy the trend of municipal solid waste (MSW) selective collection shows that the present scenario is changing towards efficiencies that can reach $65 \%$ in some regions. In this frame a big problem concerns the planning of treatment plants that could face with the variations in terms of quantity and quality of residual MSW. In order to face with the variability of the selectively collected organic fraction to be treated, composting plants are generally implemented in modules. This flexibility is an advantage when the decision for constructing a plant must be taken when selective collection is not yet steady. Anaerobic digestion is typically implemented in big bioreactors as the ratio surface/volume is more favourable if the volume is high. The anaerobic digesters are heated, thus a limited specific surface of dispersion is preferred. This characteristic gives to anaerobic digestion less flexibility than composting. Facing this disadvantage, some designers propose plants with a set of digesters both for selective collection streams and for the organic fraction automatically sorted from the residual MSW. Depending on the results of selective collection, a digester used for one stream can be switched to the treatment of the other. Bio-drying as residual MSW pre-treatment before energy recovery is performed well when the organic fraction content is high. It is clear that selective collection can be a problem for this process when it causes a low organic fraction content in the residual MSW. Bio-drying cannot develop well in this case. Bio-stabilisation before landfilling can have similar problems. Incineration is presently proposed in Italy as an option to treat the whole stream of residual MSW. Different selective collection efficiencies can change the data for designing this kind of plant. Additionally a problem is related to the high lower heating value obtainable for residual MSW if selective collection of organic fraction is successfully adopted at householder level. The conventional air cooled grate can become unsuitable.
\end{abstract}

Keywords: design, Italy, plants, residual MSW, selective collection. 


\section{Introduction}

In Italy the trend of municipal solid waste (MSW) selective collection shows a strong difference between regions. Some areas are in critical conditions in terms of MSW management: the recent crisis of Naples is an example. On the contrary other regions show spectacular results of selective collection efficiency (Ragazzi and Rada [1]). In these last areas the present scenario is changing towards efficiencies that can reach $65 \%$ also at regional level. In Figure 1 the example of the town of Trento is shown (Fedrizzi [2]).

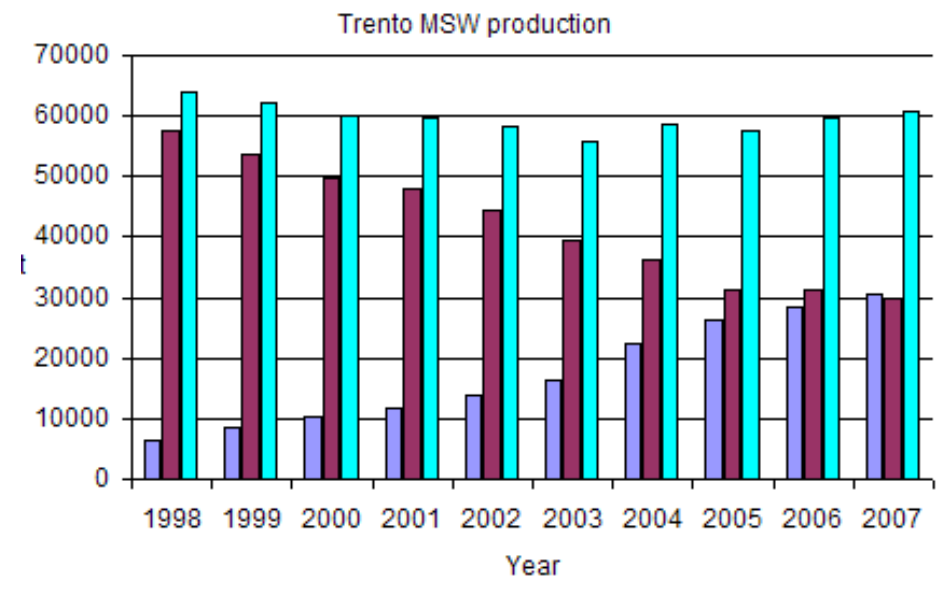

$\square$ MSW selective collection $\square$ Residual MSW $\square$ MSW production

Figure 1: $\quad$ MSW trend in Trento.

The town of Trento has about 100,000 inhabitants. Its Province (about 450,000 inhabitants) shows even better results in many municipalities. The official target is $65 \%$ of selective collection at provincial level and is expected to be reached soon. These results are generally based on the extensive activation of the door-to-door system. To this concern, some critical aspects of this strategy have been solved supporting the domiciliary collection with a parallel network of supervised "eco-points". Here a citizen can hand in its waste in case of "missed date" with the operators who collect door-to-door the separated fractions of MSW. A missed date could be critical in particular for the home management of the putrescible fraction of MSW.

In this frame a big problem concerns the planning of treatment plants that could face with the variations in terms of quantity and quality of residual MSW. Indeed a MSW management strategy based on the concept of "zero landfilling" of untreated waste means that the construction of the treatment plants must guarantee a $100 \%$ treatment potential even during a period where the streams to be treated are more of less steady in terms of total amount but vary significantly from year to year depending on the changing results of selective collection. 
In this scenario the strategies aimed to decrease the overall amount of the generated MSW seem to counterbalance the increase of production related to the demographic development. As a consequence in this paper this aspect will not be dealt with.

\section{Biological plants}

\subsection{Aerobic plants}

In order to face with the variability of the selectively collected organic fraction to be treated, composting plants are implemented in modules.

This flexibility is an advantage when the decision for constructing a plant must be taken when selective collection is not yet steady.

Apart from that, the present trend shows that small plants are preferred, but the simplification of some design criteria can cause big problems, mainly in terms of odours. Indeed in case of small plants only the accelerated fermentation stage is developed indoor, while the maturation stage is performed open air. In this situation a mistake in the management of the first stage (incomplete stabilisation) can cause high odour emissions from the material moved to the second stage, without any possibility of odour removal.

The most recent cases of opposition to composting plants because of the odour impact refer to the Strambino plant and the Levico plant both in alpine regions characterised by a strong thermal inversion during winter that causes a reduced dispersion of the emissions.

Bio-drying as residual MSW pre-treatment before energy recovery is performed well when the organic fraction content is high.

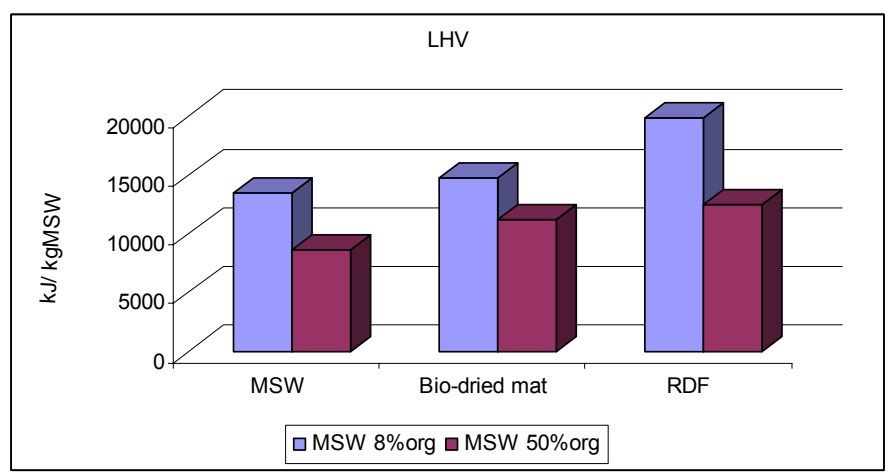

Figure 2: $\quad$ LHV dynamics in two extreme scenarios.

A comparison regarding the lower heating value between two bio-drying runs performed at pilot scale (Rada et al. [3]) is presented in Figure 2. The two cases refer to organic fraction contents of $50 \%$ and $8 \%$. 
The first case can be representative of some regions in the south of Italy where selective collection is close to zero (lower values of MSW production cause an additional increase of the percentage).

On the contrary the second case refers to regions with a high efficient organic fraction selective collection. To this concern, a few municipalities, generally in the north east of Italy, have reached these results. Similar results are expected at regional level in few years.

It is clear that selective collection can be a problem when it causes low organic fraction content in the residual MSW. Bio-drying cannot develop well in this case as explained in Figure 2, where the effect of the process on the LHV increase is moderate. Apart from this trend, Italy can be considered the second country in the world in terms of presence of bio-driers (Rada [4]).

Bio-stabilisation as landfill pre-treatment can have similar problems. This process is performed on the wet stream generated by screening of residual MSW.

The undersieve can be poor of organic fraction when residual MSW is poor too.

A controversial aspect is related to the limit of the respirometric index to be complied with in some regions (before landfilling). When the limit is not stringent there is the contradiction that the required bio-stabilisation level could be reached even with a bio-drying process. But this approach does not minimise the impact on the environment as demonstrated in Figures 3 and 4.

Indeed in Figure 3 the trend of the temperatures during bio-drying of a residual MSW with $21 \%$ of organic fraction is presented. Probe 1 refers to air temperature at the inlet; probes 2 and 3 refer to the core of the waste (in particular the probe n.2); probe 4 refers to air at the outlet.

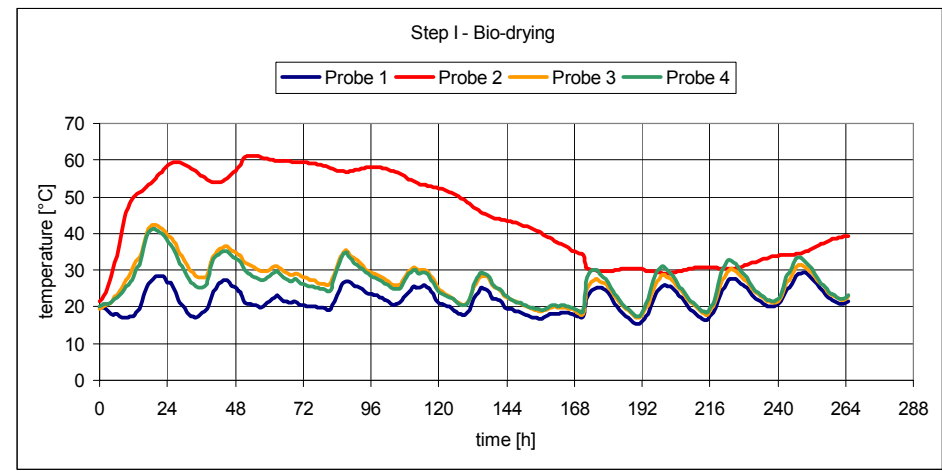

Figure 3: Temperature dynamics during the first step: bio-drying.

A demonstration that the bio-dried material is not a bio-stabilised material can be seen in Figure 4, where a bio-dried material was re-humidified to check if the biological process can be reactivated. Probes are numbered as in Figure 3. The restarting of the reaction is clear: the temperature in the core of the waste reaches again $60^{\circ} \mathrm{C}$ showing a significant biological activity in the mass. 


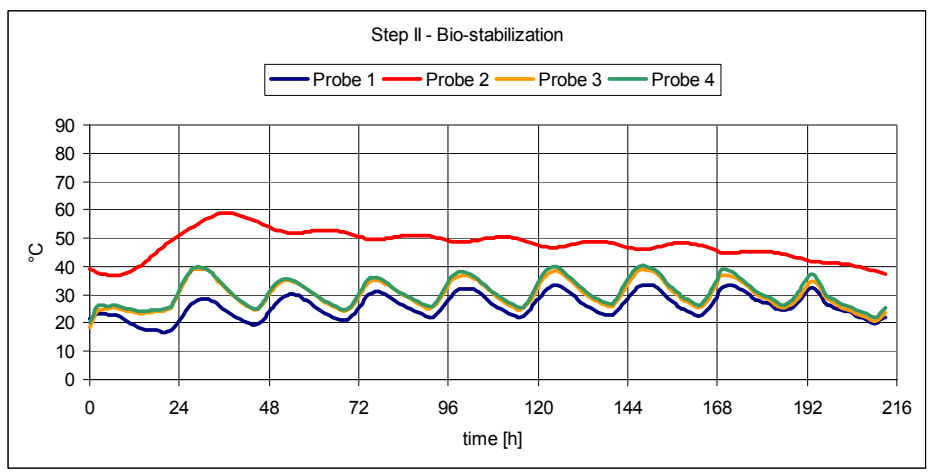

Figure 4: Temperature dynamics during the second step: bio-stabilization.

A recent research (Rada et al. [5-7]) demonstrated that a stripping of $\mathrm{PCDD} / \mathrm{F}$ into the process air can characterize the aerobic processes in the MSW sector. The strippable amount is lower than the PCDD/F emitted from a modern incinerator (Rada et al. $[5,8]$ ) but the way of release into the environment is unfavourable: low height of emission, very low gas velocity, moderate temperature. As a consequence, a verification of the health risk should be developed in particular when the plant is proposed in an agricultural area. This concept is not yet adopted at design level but the consequence could be that a biological plant could have an impact not optimised. The adoption of an adequate stack could be a good strategy to this concern as recently demonstrated by the authors (Rada et al. $[5,8]$ ).

\subsection{Anaerobic plants}

Anaerobic digestion is typically implemented in big bioreactors as the ratio surface/volume is more favourable if the volume is high: the anaerobic digesters are heated, thus a limited surface of dispersion is preferred. This characteristics gives to anaerobic digestion less flexibility than composting. To face with this disadvantage, some designers propose plants with a set of digesters both for selective collection streams and for the organic fraction automatically sorted from the residual MSW. Depending on the results of selective collection, a digester used for one stream can be switched to the treatment of the other. This is the case of the Bassano del Grappa plant, presently configured only for selected streams but originally aimed to a double stream treatment: organic fraction from selective collection and automatically sorted organic fraction from residual MSW, depending on the kind of selective collection present in each serviced area.

Apart from that, there is a general interest in co-digestion at wastewater treatment plants. A critical aspect is related to the future fate of sewage sludge as strong restrictions on agricultural use are expected and landfilling in no longer viable. As a consequence it is clear that co-digestion can divert organic matter of MSW from a potential agricultural use as the mix sludge plus MSW organic 
fraction will not be suitable for that fate because of the sludge presence. A recent proposal under discussion concerns the Rovereto plant that could be modified for co-digestion and integrated with a wet oxidation reactor in order to destroy the residual volatile solids after the biological reactor. In this case the MSW organic fraction is exploited through biogas generation and a non-agricultural fate is accepted.

\section{Thermal plants}

Incineration is presently proposed in Italy as an option to treat the whole stream of residual MSW. That means landfilling should be used only for slag and treated fly-ash. To this concern some interesting plants have been recently built in order to recycle $100 \%$ of slag. A part of that is recycled as metals; another part is treated to be used in the sector of cement works (Schiona [9]). It is clear that the option "zero landfilling" needs an additional effort: fly-ash should be treated to be recycled. Solutions for fly-ash vitrification are planned in a few Italian regions either as a unique stream or as an integrated stream. The first case concerns the planned Trento incinerator: vitrification through oxicombustion is one of the two options pointed out in the recent MSW management plan (the second one is plasma vitrification, but power consumption makes it not viable this options). The second case is the planned incinerator in Sequals: according to the planned strategy, the generated fly-ash will be treated in an integrated plant where the stream of local sewage sludge will be pyrolysed, the outcoming material will be vitrified together with fly-ash in a oxicombustor that will use a part of the generated syngas; the oxicombustor will give two streams: a glasslike material and a hot off-gas; the off gas will be used to heat the pyrolyser (with a part of the generated syngas) in order to optimise the energy balance; at the end the off gas will be sent to the main off-gas treatment line (the one of the incinerator).

In both the cases the vitrified material can be used in some industrial sectors (glass, thermal insulation, etc.). That means that, coupling this solutions with the one of slag recycling, the sector of MSW could be managed without sanitary landfills.

Different selective collection efficiencies can change data for designing incineration plants. Designer must carefully calibrate the construction of an incinerator with the expected results of selective collection. It must be pointed out that the variation in thermal power is not proportional with the variation in the percentage of selective collection efficiency. It depends on the energy content of the diverted streams.

Additionally a problem is related to the high lower heating value obtainable for residual MSW if selective collection of organic fraction is adopted with success also at householder level: the conventional air cooled grate can become unsuitable. Indeed the recent proposals for new plants in Italy seem to be oriented to the adoption of the water cooled grate.

In Italy there is a general interest for innovative solutions (gasification, pyrolysis), thus the future scenario could see some alternative plants also in real 
scale. The Japanese market is presently analysed in order to find alternatives. The interest for those solutions is related to the reduced dimensions of the plants, the possibility of integrated vitrification of slag, the generation of a syngas that could be exploited in systems at high efficiency in terms of electricity generation.

\section{Landfilling plants}

To this concern Italy seems to be divided in two. Some regions have planned to renounce to landfilling in few years thanks to the success of selective collection and to the integration of the system with an incinerator. Other regions (like Naples) are basing the strategy on new landfills in order to face with a dramatic lack of planning. In this second case the pre-treatment is compulsory. Generally until now the adopted solution is the two streams option: screening with oversieve to be directly landfilled and undersieve to be bio-stabilised and generally landfilled. To this concern a general worrying is related to the high calorific value of the oversieving.

\section{Conclusions}

Some considerations can be made from the present paper:

- $\quad$ Composting design must improve the solutions for air treatment.

- Bio-drying and bio-stabilization must be carefully designed in terms of compatibility with the strategies of selective collection and the final destination of the treated material.

- $\quad$ Anaerobic digestion shows less flexibility of composting but some design criteria can limit this problem.

- Thermal plants must be designed with particular attention to selective collection in particular when no landfill for residual MSW has been planned.

- Landfilling is viewed as a secondary actor in the future scenarios of MSW management.

\section{References}

[1] Ragazzi M., Rada E. C. Il ruolo della bioessiccazione di rifiuti urbani residui. Proc. of $63^{\circ}$ Corso di Aggiornamento in Ingegneria SanitariaAmbientale, Vol. 63, pp. XII-1-XII-19, 2008.

[2] Fedrizzi S. L'esperienza di Trento: raccolta differenziata. Proc. of La raccolta differenziata: lo stato dell'arte in Italia, 2007.

[3] Rada E. C., Ragazzi M., Fabbri L., Panaitescu V., Apostol T. Life Cycle Analisis applicata alla bioessiccazione: aspetti energetici. Rifiuti Solidi, Vol. XX, N.2, pp. 89-97, 2006.

[4] Rada E. C. Municipal solid Waste bio-drying before energy generation. PhD, University of Trento \& University Politehnica of Bucharest, 2005. 
[5] Rada E. C., Ragazzi M., Panaitescu V., Apostol T., Some research perspective on emissions from bio-mechanical treatments of municipal solid waste in Europe. Environmental Technology, Vol. 26, Nr.11, pp. 1297-1302(6), 2005.

[6] Rada E. C., Ragazzi M., Panaitescu V., Apostol T., The role of biomechanical treatments of waste in the dioxin emission inventories. Chemosphere, Vol 62/3, pp. 404-410, 2006.

[7] Rada E. C., Franzinelli A, Ragazzi M., Panaitescu V., Apostol T. Modelling of PCDD/F release from MSW bio-drying. Chemosphere, vol. 68., pp. 1699-1674, 2007.

[8] Rada E. C., Ragazzi M., Panaitescu V., Apostol T., Etudes des emisions dans l'air des traitements biomecaniques aerobie des ordures menageres. Déchets sciences \& techniques, $\mathrm{N}^{\circ} 40$, pp. 16-20, 2005.

[9] Schiona G., Il riciclo e la sostenibilità ambientale dell'alluminio. Proc. of $63^{\circ}$ Corso di Aggiornamento in Ingegneria Sanitaria-Ambientale, Vol. 63, pp. IX-1-IX-31, 2008. 